\title{
SURVIVAL AFTER JUMPING FROM THE GOLDEN HORN BRIDGE DURING A FAILED SUICIDE ATTEMPT
}

\author{
Onur Kaplan*, Özgür Söğüt*, Mustafa Öztürk*, Sümeyye Çakmak* \\ * University of Health Sciences, Haseki Research and Training Hospital, Emergency Medicine, İstanbul, Turkey
}

\begin{abstract}
Introduction: In high-altitude falls, including those related to suicide attempts, mortality varies according to the height of the jump, the rate of the fall, the structure of the ground below, as well as the position of the individual during the jump and upon impact. Individuals who unsuccessfully attempt to commit suicide by jumping off a brigde suffer traumatic injuries with potentially significant morbidity.

Case Report: Here we present the case of a 29-year-old female who survived a jump from the Golden Horn Bridge, $22 \mathrm{~m}$ above sea level.

Conclusion: The absence of major head trauma as well as laryngotracheal, cardiovascular, and major vascular injuries improved her chances of survival.
\end{abstract}

Keywords: Chest trauma, Golden Horn Bridge, suicide, survival, jumping from height

\section{Introduction}

Worldwide, suicides are responsible for the death of 800,000 people each year. Among young people (15-29 years of age), suicide was the second most common cause of death in 2015, following road traffic injuries (1). In 2015 , $78 \%$ of the recorded suicides occured in lowand middle-income countries (1). In Turkey, the number of suicides increased by $1.3 \%$ in 2015 vs. 2014 (2). The estimated suicide rate in Turkey is 4.11 per 100,000, with 3,169 suicides in 2015 (2). In one study that investigated suicides in Turkey, individuals between 20 and 28 years old most often attempted suicide, with a higher proportion of women (3). In South Korea, the number of suicide attempts at the bridge on the Han river have been rapidly increasing over the last decade from 132 persons in 2005 to 543 persons in 2015 (4).

Likewise, in Turkey, jumping from bridges, particularly the Haliç (Golden Horn) Bridge, is a common method of suicide. The Golden Horn Bridge spans a major urban waterway and the primary inlet of the Bosphorus in Istanbul. As its English name indicates, the bridge is located on the Golden Horn in Istanbul. It serves as a motorway and has a length of $995 \mathrm{~m}(3,264 \mathrm{ft})$, a width of $32 \mathrm{~m}(105 \mathrm{ft})$, and a height of $22 \mathrm{~m}(72 \mathrm{ft})$ above sea level (5).
Here, we describe the case of a person who jumped from the Golden Horn Bridge but survived, with a better-than-expected, clinically stable condition. The causes underlying her survival are discussed.

\section{Case Report}

A 29-year-old female was brought to our emergency department (ED) by the city ambulance service after she had attemped suicide by jumping from the Golden Horn Bridge, from a height of $22 \mathrm{~m}$ above sea level, into the Bosphorus Strait. She had been rescued by fishermen, who brought her to the shore. According to her history, she had been contemplating suicide for 5 years and particularly during the last year, but she had not previously attempted suicide. Three years earlier, she had been diagnosed with major depression, for which hospitalization and medication were recommended. However, the patient was not willing to accept either form of treatment because she was breastfeeding a baby. She had known bile duct stones and parathyroid adenomas and was not currently taking any medication. The patient was brought to the emergency room with a neckstrap attached and lying on a trauma table. Her Glasgow Coma Scale score was 15 and her Injury Severity Score was 14 . Injuries to the chest, lumbar region, and left elbow were documented together with minimal abdominal pain. 
On presentation to the $E D$, she had a blood pressure of $120 / 70 \mathrm{~mm} \mathrm{Hg}$, a pulse rate of 90 beats per min, and a respiratory rate of 24 per min. Her body temperature was $36.0^{\circ} \mathrm{C}$, and her oxygen saturation while breathing room air was $98 \%$. She weighed $110 \mathrm{~kg}$. The airway was intact and she had minimal tachypnea, but no dyspnea or cyanosis. Her abdominal and respiratory examinations were normal. A hemogram revealed leukocytosis, and urinalysis indicated microscopic hematuria.

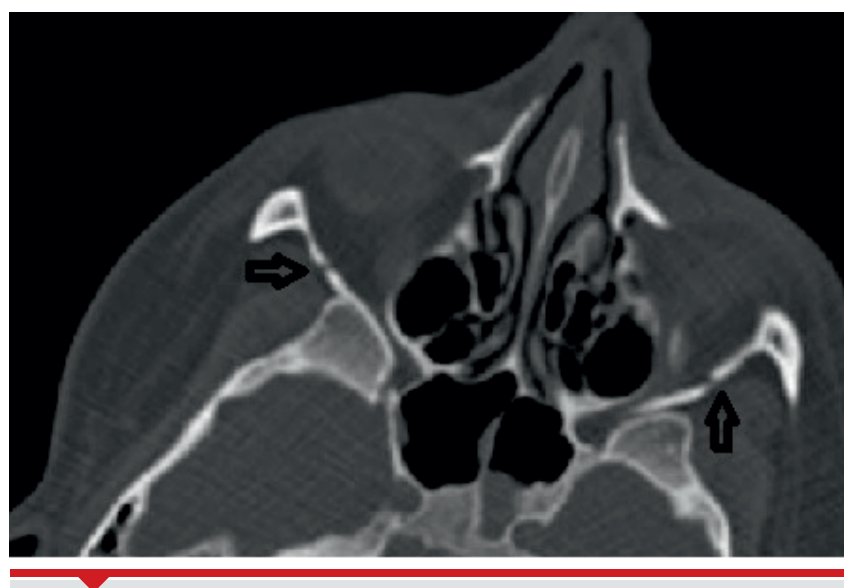

FIGURE 1. Computed tomography scan of the cranium showing linear bilateral fractures of the lateral orbital wall (arrows).

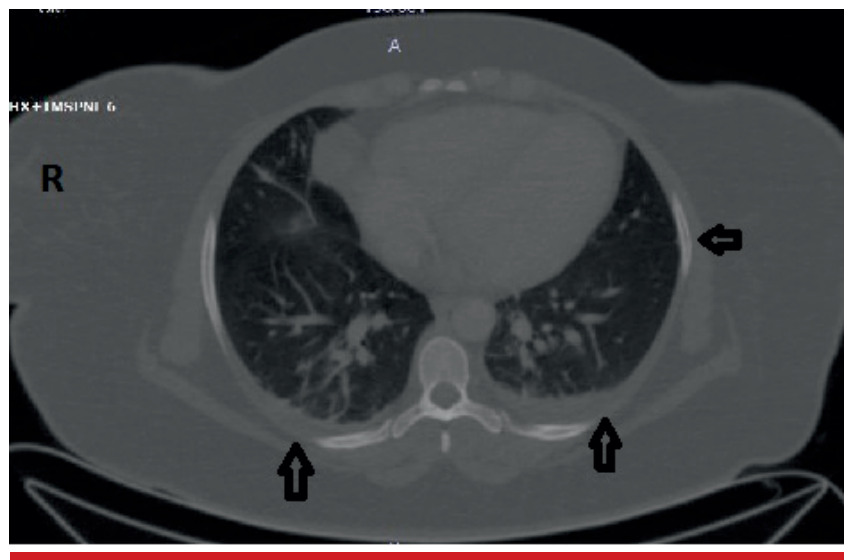

FIGURE 2. A chest computed tomography shows a left fifth rib fracture and bilateral minimal hemothorax (arrows).

Her X-ray (chest, servical and lomber vertebra, pelvis, and extremity) imaging findings were normal but a cranial computed tomography (CT) scan revealed linear fracture lines on the orbital lateral wall bilaterally (Figure 1). Contrast-enhanced abdominal CT did not reveal any traumatic pathology. In thoracic $\mathrm{CT}$, fracture of the left fifth rib and bilateral minimal hemothorax were seen (Figure 2). The patient was hospitalized by the chest surgeon for treatment, including thoracic surgery and follow-up. On day 8 of her hospitalization, a second thoracic CT scan showed that her injuries had regressed. Ten days after thoracic surgery, the general condition of the patient had improved and no complications had developed. After consultation with the psychiatry department, transfer of the patient to the psychiatric service to address her suicidal state was planned.

\section{Discussion}

This index case focuses on managing a patient who survived a jump from the Golden Horn Bridge, $22 \mathrm{~m}$ above sea level during a failed suicide attempt.

Attempts to commit suicide by jumping from a height result in different mortality rates and types of injury, depending on the jumping height. At a height of up to 7 $\mathrm{m}$, the mortality rate is $13-32 \%$, while at heights from 7 to $30 \mathrm{~m}$ the rate is $64-81 \%$, and from greater heights (above $30 \mathrm{~m}$ ) it is $96-100 \%$ (6). According to Buckman et al., (7) jumping off bridges higher than $15 \mathrm{~m}$ almost always results in death. The mortality rates following jumps from the Gateway Bridge $(65 \mathrm{~m})$, the Sydney Harbour Bridge (59 m), the Seattle Aurora Bridge (50 m), and the Story Bridge $(30 \mathrm{~m})$ are $94 \%, 85 \%, 87 \%$, and $75 \%$, respectively (8-10). In a study of suicides from the Bosphorus Bridge, Cetin et al. (5) found that 2 of the 65 individuals who jumped from the bridge between 1986 and 1995 survived, corresponding to a mortality rate of $96.9 \%$. Mortality due to a jump is determined by the height of the bridge, the velocity of the fall, the body's position upon jumping and upon impact, wind speed and direction, clothing, water temperature, and wave conditions $(11,5)$.

The most common injury after a fall is blunt trauma to the chest. The number of ribs fractured is an indicator of the severity of the injury. Rib fractures occur by direct compression (6). Our patient fell onto the lateral aspect of the thorax. Although her position during the jump was unfavorable and the bridge is quite high, she survived, albeit for reasons that are unclear. She attempted suicide in winter, on a cold and windy day. The water temperature of the Golden Horn is low and she was dressed in tight-fitting clothing. With a weight of $110 \mathrm{~kg}$, she had considerable body fat. The wind strength and her type of clothing affected her falling velocity, while the wave height, her tight-fitting clothes, the cold water temperature (resulting in hypothermia), and her considerable body fat may have reduced the impact strength and increased her chances of survival. 


\section{Conclusion}

Failed suicide attempts following a jump from a bridge are a medical emergency. Factors preventing death include the jump height, the patient's clothing and weight, and the water temperature. The Golden Horn bridge is $22 \mathrm{~m}$ above sea level such that most jumps result in death. In our patient, the absence of major head trauma as well as laryngotracheal, cardiovascular, and major vascular injuries contributed to her survival.

\section{References}

1. World Health Organization April 2016 Suicide Fact Sheet. Available at: http://www.who.int/mediacentre /factsheets/fs398/en/ (cited 11 May 2016).

2. Suicide Statistics, 2015. Turkish Statistical Institute Newsletter. Available at: http://www.tuik.gov.tr/PreHaberBultenleri.do?id=18626 (cited 17 June 2016).

3. Sogut O, Sayhan MB, Gökdemir MT, Kaya H, Al B, Orak M, et al. Evaluation of Suicide Attempts in Southeast of Turkey, Around the Sanliurfa Region. Eurasian J Emerg Med 2011; 10: 8-13.

4. Kim K, Jeon HJ. Frontal Lobe Dysfunction in a Depressed Patient Who Survived a Suicide Attempt by Jumping from the Bridge on the Han River. Psychiatry Investig 2017; 14: 904-8.

5. Cetin G, Günay Y, Fincanci SK, Ozdemir Kolusayin R. Suicides by jumping from Bosphorus Bridge in Istanbul. Forensic Sci Int 2001; 116 : 157-62.

6. Atanasijevic TC, Popovic VM, Nikolic SD. Characteristics of chest injury in falls from heights. Legalmed 2009; 11:315-7.

7. Buckman RF, Buckman PD. Vertical deceleration trauma. Principles of management. Surg Clin North Am 1991; 71: 331-4.

8. Harvey PM, Solomons BJ. Survival after free falls of 59 metres into water from the Sydney Harbour Bridge, 1930-1982. Med J Aust 1983; 1 :504-11.

9. Cantor $\mathrm{CH}$, Hill MA, McLachlan EK. Suicide and related behaviour from river bridges. A clinical perspective Br J Psychiatry 1989; 155: 82935.

10. Robertson HT, Lakshminarayan S, Hudson LD. Lung injury following a 50-metre fall into water. Thorax. 1978; 33: 175-80.

11. Erdogan MO, Sogut O, Yorulmaz R, Gokdemir MT, Tayfur I. Surviver of Suicidal Fall from the Bosphorus Bridge. JAEMCR 2013; 4: 22-4. 